\title{
Analysis of gait transitions in dressage horses using wavelet analysis of dorsoventral acceleration
}

\author{
Sophie Biau, Sophie Lemaire and E. Barrey? \\ Ecole Nationale d'Equitation Terrefort and 'INRA Station de Génétique Quantitative et Appliquée - Groupe cheval, Jouy-en-Josas
}

\begin{abstract}
Summary
The purpose of this study was to describe downward gait transitions in dressage horses using wavelet analysis spectrum of dorsoventral acceleration. An accelerometric device fixed at the sternum measured the dorsoventral and longitudinal acceleration of the running horse. Eighteen horses trained for dressage at the national level were recorded during dressage tests. Nine variables were calculated from a Morlet's wavelet analysis at canter-trot, canter-walk, canter-halt, trot-walk, trot-halt and walk-halt transition. These variables quantified the transition duration, the energy and the frequency of the dorsoventral acceleration during the gait transition. The variables distinguished each type of transition $(P<0.05)$. It was found that the transition duration increased and variation of energy and frequency were minimised with dressage training.
\end{abstract}

Keywords: $\quad$ horse, acceleration, gait, wavelet analysis

\begin{abstract}
Analyse der Phasenübergänge in der Dressur mit Hilfe der Wavelet-Analyse der dorsoventralen Beschleunigung
Die Studie beschäftigt sich mit den abnehmenden Phasenübergängen der unterschiedlichen Gangarten bei Dressurpferden. Die von einem am Brustbein befestigten Beschleunigungsaufnehmer aufgenommenen dorsoventralen Beschleunigungen werden mit Hilfe einer WaveletTransformation analysiert. Diese Transformation ermöglicht es, neun Variabeln zu errechnen, die die Übergangsdauer, die Energie beim Abbremsen und die dorsoventrale Aktivität und Frequenz kennzeichnen. Fünf vieriährige, drei sechsiährige und sieben auf nationalem Niveau gehende Dressurpferde führten die verschiedenen abnehmenden Gänge vor, nämlich Galopp-Trab, Galopp-Schritt, Galopp-Halt, TrabSchritt, Trab-Halt und Schritt-Halt. Der Einfluss der Dressur und des Pferdegangtyps auf die Variablen wurde mit einer Varianzmethode analysiert. Die errechneten Variablen erlauben es, die verschiedenen Übergänge zu unterscheiden. Der Übergang von Schritt zu Halt ist der längste, und ergibt die geringste dorsoventrale Aktivität, und das schwächste Abbremsen. Der Übergang von Trab zu Schritt ist der kürzeste und ist durch starkes Abbremsen gekennzeichnet. Der Einfluss des Trainings hängt vom Gangtyp ab. Die Dressurregeln bevorzugen einen möglichst geschmeidigen Übergang, ohne Kadenzänderung oder Rythmusbruch. Diese Geschmeidigkeit wird durch eine frühe Gangabnahme erreicht. Die Konsequenz ist ein schwächeres Abbremsen. Der Übergang davert dann länger, ist aber dafür um so geschmeidiger. Die Wavelet-Analyse des Beschleunigungsignals erlaubt es, die kinetischen Eigenschaften des Übergangs zu ermitteln. Diese Methode berücksichtigt auch Frequenz und Energieänderungen, die dem Auge oder kinematischen Studien verborgen bleiben.
\end{abstract}

Schlüsselwörter: Pferd, Gangart, Beschleunigung, Wavelet-Analyse, Ganganalyse

\section{Introduction}

Gait transition is one of the most difficult basic exercises in dressage. It has been described by riders with pendulum image (Barroil, 1887) and studied with kinematic measurements for the first time with Marey (1873). From a dynamical point of view, a gait transition can be characterised by a gait change with non stationary motions of the limbs. Periodicity and rythm of the limb motions change suddenly. Transient phenomenon is not easy to analyse quantitatively because most of the methods of signal analysis like Fourier transform require continuous phenomenon with statistical stationary properties. Wavelet analysis is an adequate tool to study non stationary signals like the acceleration recordings of the body during a specific exercise. This method has been used in human locomotion to discriminate the type of walking (Tamura, 1997) or to identify walking irregularities (Auvinet et al., 2000). In horse, wavelet analysis has been applied for measuring jumping ability (Barrey et al., 1997), gaits in harness racing and dressage (Barrey et al., 2000) and for describing hoof impact (Burn, 1997).

Trot-canter transition has been trigged by musculoskeletal forces critical level (Farley, 1991). The kinematic of walk-trot and trotwalk transition has been described in literature (Argue and Clayton, 1993) and showed the influence of the level of training. However, few data are available to understand the gait transitions which are scored by the judge in dressage competitions. By using body acceleration measurement of dressage horses and wavelet analysis methods, it was possible to describe gait transitions quantitatively. The purpose of this study was to measure gait transitions using a wavelet analysis. We hypothesised that age and dressage training has an influence on the gait transition technique. The kinetic characteristics of the walk-halt, trot-halt, canter-halt, canter-trot, canter-walk and trot-walk transition were measured in dressage competitions.

\section{Materials and methods}

Fiffeen horses were tested: five 4 year old, three 6 year and seven experienced horses of dressage national level. The horses were equipped with the ambulatory gait analysis system Equimetrix ${ }^{\mathrm{TM}}$. The recordings were made during dressage events. Two types of dressage tests were studied: one type was used for young horses (4 year old) and the other type was used for experienced horses. Four year old horses performed dressage test with walk-halt, trothalt, trot-walk, canter-trot transitions. Six year old horses performed in addition canter-halt and canter-walk transition. In summary the following decelerating gait transitions were studied:

- Canter-trot (CT): 16 transitions executed by 4, 6 year and experienced horses

- Canter-walk (CW): 10 transitions executed by 6 year and experienced horses 
- Canter-halt $(\mathrm{CH}): 33$ transitions executed by 6 year and experienced horses

- Trot-walk (TW): 28 transitions executed by 4, 6 year and experienced horses

- Trot-halt (TH): 33 transitions executed by 4, 6 year experienced horses

- Walk-halt (WH): 10 transitions executed by 4, 6 year and experienced horses

\section{Accelerometric device}

The gait analysis system Equimetrix' was composed of an acceleration transducer connected to a small data logger which has been used previously in jumping test (Barrey and Galloux, 1997). The transducer was composed of two orthogonal accelerometers which measured the thorax acceleration continuously along the dorsoventral and longitudinal axes of the horse. It was fixed to the girth of the saddle against, the sternum. This location was adapted to capture general information about kinetics of the gait. It was located between the right and left muscles pectoralis ascendens about $60 \mathrm{~cm}$ down and front to the horse's center of gravity (Galloux and Barrey, 1997). Acceleration values were positive during the stance phase and negative during the suspension phase. The accelerometers were connected to a small data logger placed into a pocket of the saddle pad. The data acquisition rate was 50 Hertz for $10 \mathrm{~min}$. After recording, data were transferred to a computer for analysis.

\section{Data analysis}

A Fourier transform of a signal provides frequency, energy and phase characteristics of the signal but it is not adapted for transient events. A Fourier analysis was adapted to study periodic and stationary signals of gait but cannot determine discontinuities or progressive variations in energy or frequency. It is impossible to locate a transient event and to determine beginning and end of this event. Mathematical procedure has been developed to describe non stationary signals with transitory characteristics. The procedure used a wavelet function which calculated a time frequency decomposition. The signal was compared to a wavelet at different scales by compressing and expanding the mother wavelet and at different time by delaying the mother wavelet. The scale corresponded to the signal frequency and the position corresponded to the time. The result were wavelet coefficients. A small one represented a signal change. A large one represented similarity with the mother wavelet. Using the coefficients, a three dimensional power spectrum could be plotted to show the analysis in time, frequency and module of energy of the signal. The mother wavelet chosen was a Morlet's wavelet which was well adapted for signal including low frequency phenomenon like in gait analysis. A Morlet's wavelet analysis was computed for each dressage test transition. The following variables were defined for quantifying the time frequency energy spectrum of a Morlet's wavelet analysis obtained for each type of transition (figure 1 and 2).

\section{Transition duration (s)}

Time elapsed between the first kinetical change before the gait transition and until the kinetical stability of the second gait was reached. Kinetical change before the gait transition means that either energy module or frequency change was observed on the spectrum. The stability was reached as soon as both frequency and energy module were constant.

\section{Dorsoventral activity $(\mathrm{g} " / \mathrm{Hz})$}

Dorsoventral activity (integral of the power spectrum of the wavelet analysis) of the dorsoventral acceleration signal during the transition.

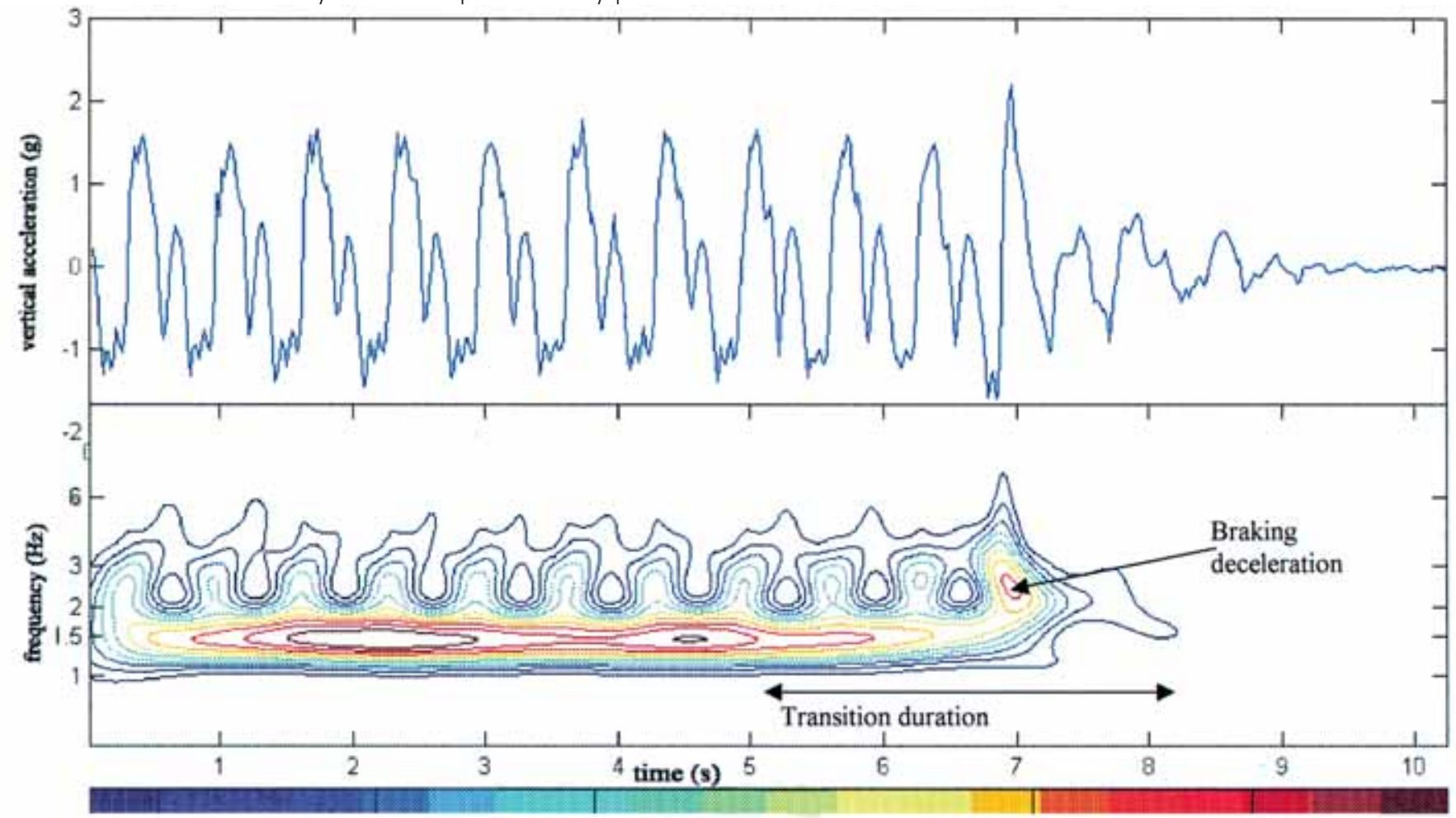

Fig. 1: Canter-halt transition: dorsoventral acceleration and time-frequency-energy image of Morlet's wavelet analysis.

Galopp-Halt - Übergang: dorsoventrale Akzeleration und Zeit-Frequenz-Energie-Bild der Morlet's Wavelet-Analyse 
Averaged energy $\left(\mathrm{g}^{\prime \prime} / \mathrm{Hz}^{\prime \prime}\right)$

Mean energy module of the Morlet's wavelet during the transition.

Averaged energy variation $\left(\mathrm{g}^{\prime \prime} / \mathrm{Hz}\right.$ ")

Standard deviation of averaged energy module of the Morlet's wavelet analysis during the transition.

Braking deceleration ( $\mathrm{g}^{\prime \prime} / \mathrm{Hz}$ ")

Difference of energy module between the maximum and minimum energy value during the transition.

Averaged frequency (\% a. f.)

First order time moment of the Morlet's wavelet analysis. The acquisition frequency was 50 Hertz

Averaged frequency variation (\% a. f.)

Second order time moment of the Morlet's wavelet analysis.

Frequency fluidity

Correlation coefficient between averaged frequency and transition time.

\section{Energy fluidity}

Correlation coefficient between averaged energy module and transition time.

The dressage rules describe gait transition without brusqueness neither cadence change. For a smooth gait transition, the corresponding kinetical changes should be a small averaged energy and frequency variation between transition duration and averaged frequency. The following correlation coefficients measured this linear relationship: energy fluidity and frequency fluidity. The initial gait speed was not directly measured but was proportional to dorsoventral acceleration which was used to calculate variables.

\section{Statistical analysis}

Descriptive statistics were presented. The effect of transition type and training level were tested for all the variables with a variance analysis and significance set to $p<0.05$. Kendall correlation analysis was computed to study the relationships between variables $(p<0.0001)$.
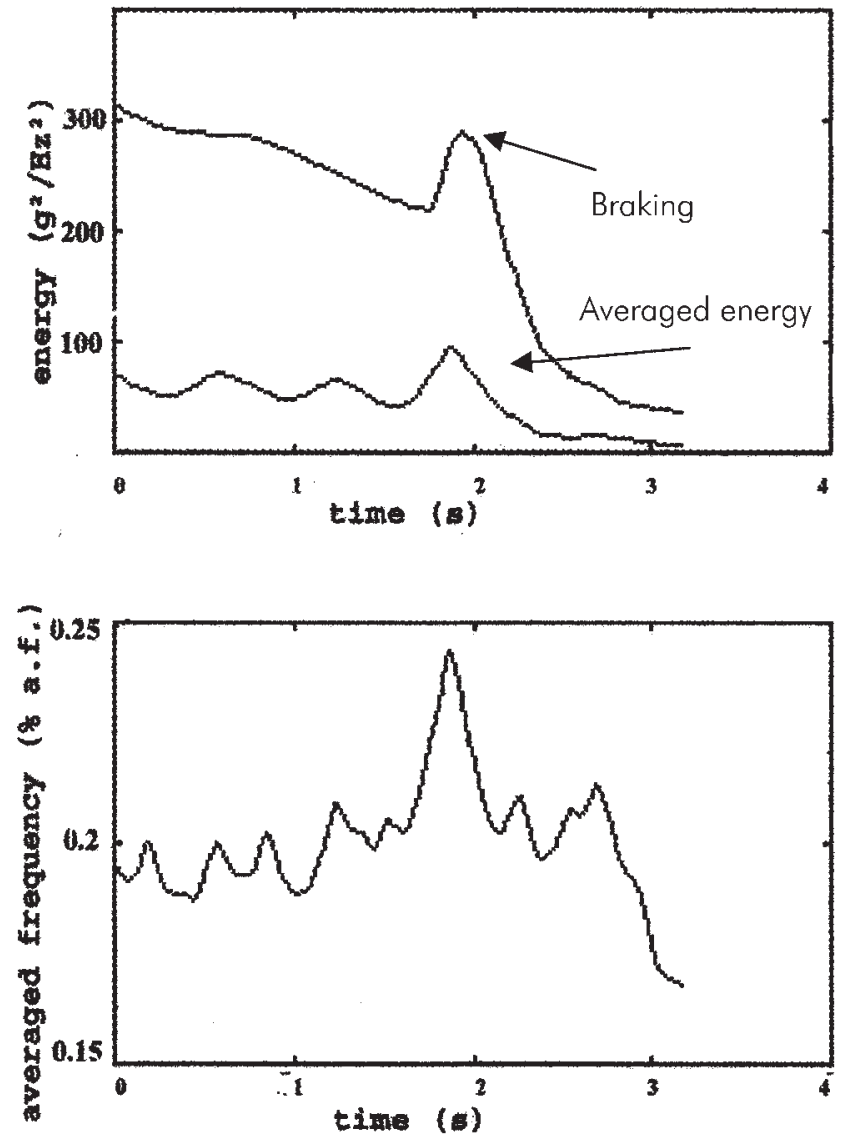

Fig. 2: Averaged energy and averaged frequency of canter-halt transition shown in figure 1. Averaged energy and averaged maximum energy shows braking deceleration in transition.

Mittlere Energie und mittlere Frequenz des Galopp-Halt-Übergangs aus Abb. 1. Die mittlere Energie und die mittlere Maximalenerigie zeigen im Übergang negative Beschleunigung

\section{Results}

\section{Transition type influence}

Means and standard deviations were presented in table 1. All the variables were significantly influenced by the transition type. Duration, energy module and frequency characterised each transition type.

Tab1: Mean ( \pm sd) values for time-frequency-energy variables of sixteen horses transitions.

Mittlere Zeit-Frequenz-Energie-Variablen für die Phasenübergänge von 16 Pferden

\begin{tabular}{|l|c|c|c|c|c|c|}
\hline Variables & Canter-halt & Canter-walk & Canter-trot & Walk-halt & Trot-halt & Trot-walk \\
\hline Transition duration $(\mathbf{s})$ & $3.7 \pm 1.3$ & $4.1 \pm 1.5$ & $3.9 \pm 1.4$ & 4.71 .4 & $2.6 \pm 0.9$ & $2.7 \pm 1$ \\
\hline Braking deceleration $(\mathbf{g} \Delta / \mathrm{Hz} \Delta)$ & $175.5 \pm 39.4$ & $193 \pm 30$ & $153 \pm 79$ & $23.7 \pm 16.9$ & $225 \pm 62$ & $206.5 \pm 79$ \\
\hline Dorsoventral activity $(\mathbf{g} \Delta / \mathrm{Hz})$ & $5180 \pm 1956$ & $6243 \pm 2881$ & $7230 \pm 2818$ & $591 \pm 244$ & $3619 \pm 1621$ & $3447 \pm 1803$ \\
\hline Averaged energy $(\mathbf{g} \Delta \mathrm{Hz} \Delta)$ & $28.3 \pm 6$ & $29.4 \pm 5$ & $38.4 \pm 15$ & $2.8 \pm 1.6$ & $27.8 \pm 8.4$ & $25.8 \pm 10.5$ \\
\hline Averaged energy variation $(\mathbf{g} \Delta / \mathrm{Hz} \Delta)$ & $10.8 \pm 3.1$ & $12 \pm 2.7$ & $7.9 \pm 2.4$ & $1.6 \pm 1.4$ & $11.6 \pm 4.2$ & $11 \pm 4.5$ \\
\hline Averaged frequency $(\%$ a.f.) & $0.202 \pm 0.01$ & $0.203 \pm 0.008$ & $0.218 \pm 0.009$ & $0.202 \pm 0.006$ & $0.232 \pm 0.007$ & $0.235 \pm 0.006$ \\
\hline Averaged frequency Variation $(\%$ a.f.) & $0.015 \pm 0.003$ & $0.015 \pm 0.004$ & $0.025 \pm 0.004$ & $0.017 \pm 0.005$ & $0.017 \pm 0.005$ & $0.014 \pm 0.004$ \\
\hline energy fluidity & $-0.65 \pm 0.24$ & $-0.712 \pm 0.277$ & $-0.219 \pm 0.449$ & $-0.867 \pm 0.066$ & $-0.768 \pm 0.282$ & $-0.846 \pm 0.159$ \\
\hline frequency fluidity & $0.198 \pm 0.4$ & $0.122 \pm 0.4$ & $0.827 \pm 0.12$ & $0.171 \pm 0.27$ & $-0.542 \pm 0.41$ & $0-0.649 \pm 0.2$ \\
\hline
\end{tabular}


Gait transitions including canter (canter/trot, canter/walk, canter/halt) were the transition type which had the highest dorsoventral activity. Then, a second level of dorsoventral activity was observed for the transition including trot (trot/halt, trot/ walk). The range of transition duration was comprised between
$2.6 \pm 0.9 \mathrm{sec}$ (trot/halt) and $4.1 \pm 1.5 \mathrm{sec}$ (canter/walk). The braking deceleration was the lowest for walk/halt transition and the highest for trot/walk transition.

In all the transitions, the energy module decreased and energy fluidity was negative. The averaged frequency decreased for

Tab. 2: Mean ( $\pm \mathrm{sd})$ of transition variable for horse age $(*$ difference significant among 4 year old, 6 year old and experienced horses at $\mathrm{p}<0.05)$. Mittelwerte der Phasenübergänge bezüglich des Alters

\begin{tabular}{|c|c|c|c|c|c|c|}
\hline & Canter-halt & Canter-walk & Canter-trot & Trot-halt & Trot-walk & walk-halt \\
\hline \multicolumn{7}{|l|}{ Transition duration (s) } \\
\hline 4 year old & & & $3.8 \pm 1^{*}$ & $3 \pm 1.2$ & & $3 \pm 1.2$ \\
\hline 6 year old & $2.8 \pm 1.1^{*}$ & $3.8 \pm 1.2$ & $2.3 \pm 0.79^{*}$ & $2.26 \pm 0.86$ & $2.7 \pm 0.75^{*}$ & $2.26 \pm 0.86$ \\
\hline Experienced horses & $4 \pm 1.2^{*}$ & $4.8 \pm 2.1$ & $5.7 \pm 0.68^{*}$ & $2.86 \pm 0.74$ & $3.3 \pm 1.3^{*}$ & $2.86 \pm 0.74$ \\
\hline \multicolumn{7}{|l|}{ Brakina $(\mathrm{a} \Delta \mathrm{Hz} \Delta)$} \\
\hline 4 year old & & & $156 \pm 74.7$ & $170.3 \pm 30^{*}$ & $217.6 \pm 92^{*}$ & $23 \pm 22.7$ \\
\hline 6 year old & $189.2 \pm 44.6$ & $181 \pm 29 *$ & $75.3 \pm 21.8$ & $244 \pm 67.7^{*}$ & $225.7 \pm 77^{*}$ & $24.7 \pm 8.4$ \\
\hline Experienced horses & $170 \pm 37.2$ & $220 \pm 6^{*}$ & $219.6 \pm 80.4$ & $229.6 \pm 46.5^{*}$ & $174 \pm 33.8^{*}$ & \\
\hline \multicolumn{7}{|l|}{ Dorsoventral activity $(\mathrm{g} \Delta / \mathrm{Hz})$} \\
\hline 4 year old & & & $7540 \pm 2515^{*}$ & $3475 \pm 1571$ & $3290 \pm 1834$ & $593 \pm 329$ \\
\hline 6 year old & $4043.4 \pm 1758$ & $5753 \pm 2775$ & $3724 \pm 1271^{*}$ & $3500 \pm 1759$ & $3502 \pm 1188$ & $588 \pm 120$ \\
\hline Experienced horses & $5622 \pm 1891$ & $7347 \pm 3215$ & $9397 \pm 2409^{*}$ & $3940 \pm 1490$ & $3731 \pm 2108$ & \\
\hline \multicolumn{7}{|l|}{ Averaged energy variation $(\mathrm{g} \Delta \mathrm{Hz} \Delta)$} \\
\hline 4 year old & & & $7.8 \pm 2.4$ & $9 \pm 2 *$ & $11.3 \pm 4.8$ & $1.6 \pm 1.9$ \\
\hline 6 year old & $13.3 \pm 4.5^{*}$ & $12.1 \pm 2.5$ & $6.3 \pm 0.6$ & $13 \pm 4.8^{*}$ & $13.8 \pm 5.4$ & $1.5 \pm 0.57$ \\
\hline Experienced horses & $9.8 \pm 1.8^{*}$ & $12 \pm 3.5$ & $10 \pm 2.6$ & $10.6 \pm 2.7^{*}$ & $8.9 \pm 2$ & \\
\hline \multicolumn{7}{|l|}{ Averaged frequency(\% a.f.) } \\
\hline 4 year old & & & $0.219 \pm 0.011$ & $0.239 \pm 0.004$ & $0239 \pm 0004^{*}$ & $0.2 \pm 0.006$ \\
\hline 6 year old & $0211 \pm 0009^{*}$ & $0.205 \pm 0.006$ & $0.218 \pm 0.007$ & $0.230 \pm 0.006$ & $0232 \pm 0004^{*}$ & $0.197 \pm 0.011$ \\
\hline Experienced horses & $0198 \pm 0007^{*}$ & $0.197 \pm 0.011$ & $0.217 \pm 0.01$ & $0.231 \pm 0.006$ & $0229 \pm 0004^{*}$ & \\
\hline \multicolumn{7}{|c|}{ Averaged frequency Variation(\% a.f.) } \\
\hline 4 year old & & & $0.027 \pm 0.002^{*}$ & $0.015 \pm 0.004$ & $0.013 \pm 0.003$ & $0.019 \pm 0.005$ \\
\hline 6 year old & $0.015 \pm 0.004$ & $0.015 \pm 0.004$ & $0.025 \pm 0.02 *$ & $0.018 \pm 0.006$ & $0.016 \pm 0.003$ & $0.014 \pm 0.003$ \\
\hline Experienced horses & $0.015 \pm 0.003$ & $0.016 \pm 0.001$ & $0.019 \pm 0.002^{*}$ & $0.017 \pm 0.005$ & $0.014 \pm 0.004$ & \\
\hline \multicolumn{7}{|l|}{ Frequency fluidity } \\
\hline 4 year old & & & $0.866 \pm 0.033^{*}$ & $-0.663 \pm 0.18$ & $-0.659 \pm 0.2$ & $-0.268 \pm 0.129$ \\
\hline 6 year old & $-0.18 \pm 0.43^{*}$ & $-0.04 \pm 0.4^{*}$ & $0.879 \pm 0.06^{*}$ & $-0.441 \pm 0.527$ & $0634 \pm 0174$ & $-0.051 \pm 0.371$ \\
\hline Experienced horses & $0.34 \pm 0.29^{*}$ & $0.49 \pm 0.16^{*}$ & $0.605 \pm 0.2^{*}$ & $-0.636 \pm 0.224$ & $0638 \pm 0293$ & \\
\hline \multicolumn{7}{|l|}{ Energy fluidity } \\
\hline 4 year old & & & $-0.276 \pm 0.439$ & $-0.881 \pm 0.1$ & $0881 \pm 0153$ & $0821 \pm 0043^{*}$ \\
\hline 6 year old & $-0644+027$ & $-647+0.315$ & $-0.370+0.478$ & $-0795+029$ & $0877 \pm 0175$ & $-0.925 \pm 0.03^{*}$ \\
\hline Experienced horses & $-0652+024$ & $-0860+0025$ & $0.177+0.373$ & $-0635+0.32$ & $0757 \pm 0140$ & \\
\hline
\end{tabular}


trot-halt and trot-walk transition during the trot and increased for canter-halt, canter-walk and canter-trot transition during canter (positive symbol for the correlation coefficient frequency fluidity). Standard deviation was large for the frequency fluidity variable except in canter-trot transition. This variation should be the smallest for a good transition. Frequency fluidity was higher for canter-trot transition. Energy fluidity was higher for walk-halt transition.

The Kendall correlation coefficient showed that dorsoventral activity was positively correlated with transition duration $(R=0.530, p<0.0001)$ especially for experienced horses $(R=0.924)$. It took more time to decelerate and change the gait when the energy of the first gait was high.

\section{Training influence}

For each transition, the results were compared for each group of horses: 4 year old, 6 year old and experienced (Tab. 2) with a variance analysis $(p<0.05)$. Canter-halt, canter-walk, can- ter-trot, trot-halt and trot-walk transitions were improved with dressage training. Walk-halt transition characteristics were stable. The transition duration, energy and frequency transition were significantly $(p<0.05)$ influenced by the dressage training.

Dorsoventral activity increased significantly with training $(p<0.05)$. Averaged energy variation, averaged frequency and averaged frequency variation decreased significantly with training $(p<0.05)$. For all transition type, either braking deceleration or transition duration increased significantly with training.

\section{Discussion}

The gait analysis system Equimetrix ${ }^{1}$ has been used previously in harness racing evaluation (Barrey, 1995), and gaits comparison of various breeds used for dressage (Barrey, 2000). Wavelet analysis has been used for jumping test analysis to discriminate good and bad jumping skill (Barrey, 1997). For 
dressage gait analysis, the system was easy to use in competition condition and the wavelet analysis was an interesting mean to analyse complex dressage figures like gait transitions.

The horse sample was heterogeneous. It was adapted to study the improvement of the transition technique with age and dressage training but not for evaluating optimal gait transitions in elite dressage horses.

The results showed that the variables measured on the spectrum of wavelet analysis were significantly influenced by the type of transition. The walk-halt transition was characterised by the largest transition duration, the lowest dorsoventral activity, a low braking deceleration and averaged energy. The change of the energy module during this transition was fluid but the decrease of frequency was non continuous.

The trot-walk transition was characterised by a short duration with a large braking deceleration and a great averaged energy variation. A short transition duration produced an increase of braking deceleration. An increase of transition duration allowed a smooth transition with lower braking deceleration.

Canter-halt, canter-walk and canter-trot transitions were characterised by a great dorsoventral activity and a middle braking deceleration. It was explained by progressive decrease of dorsoventral activity before the gait change which minimised the braking deceleration at the end of the canter, especially for experienced horses.

a positive correlation between a higher level of training and transition without intermediate step. Acceleration recording associated with Morlet's wavelet analysis allowed to detect gait change both in duration, frequency of limb footfalls and dorsoventral energy. The influence of dressage training showed that technical improvement was not the same for all transition types. The transition duration increased significantly with training for trot-walk, canter-halt and canter-trot transitions. The lengthening of these transition allowed a decrease of frequency variation (canter-trot transition) or a decrease of energy variation (canter-halt and trot-halt transition). The rider adapted his technique to locomotion and behaviour of the horse. The beginning of energy change observed in the wavelet spectrum corresponded to the preparation of transition which took place earlier in experienced horses than for young horses. By lengthening transition duration, experienced horses could perform a smooth deceleration. In contrast, young horses could not prepare their gait transition and should suddenly brake which produce a high peak of deceleration.

The increase of dorsoventral activity with age corresponded to a morphological (weight and musculature) and a technical change (more dorsoventral displacement and elasticity). The change of transition duration and braking with training controlled this increase of dorsoventral activity. Farley and Taylor (1991) described the energetic mechanism of natural gait transition. Gait transition is triggered when musculoskeletal forces reach a critical level. In dressage, this natural trigger disappeared in favour of a specific coordination learnt during training.

Averaged frequency decreased with training for all transitions especially for canter-halt and trot-walk transition. Result of frequency fluidity variables showed a great evolution of frequency during transition between 6 year old and experienced horses. Canter-halt and canter-walk became more fluid with training.

\section{Conclusion}

The combination of gait analysis by accelerometric measurement and wavelet analysis allowed to describe quantitatively some temporal and kinetic characteristics of gait transitions. Morlet's wavelet analysis showed change of frequency and dorsoventral activity which could not be measured by the eyes or kinematic study. Transition duration, dorsoventral activity and frequency were specific for each transition. Training improved smoothness of braking deceleration and frequency changes with a longer transition duration.

\section{Manufacturer's addresses}

1 Equimétrix ${ }^{\mathrm{TM}}$, Centaure Metrix,

2 Rue Gambetta, 77210 Avon-Fontainebleau, France. E-mail: jcfabre@wanadoo.fr

\section{Literature}

Auvinet, B. and E. Barrey (2000): L'analyse par ondelettes: nouvelle méthode de quantification des anomalies de la marche. Revue de Rheumatologie 67, 817

Argue, C. K. and Hilary M. Clayton (1993): A preliminary study of transitions between the walk and trot in dressage horses. Acta Anat 146, 179-182

Barrey E. (1997): Application of wavelet analysis for studing complex motions in athletic horse locomotion. Word congress on medical physics and biomedical engineering, september 14-19, Nice. Medical \& Biological engineering \& Computing vol. 35, Suppl. part 1, 176

Barrey, E. and P. Galloux (1997): Analysis of the jumping technique by accelerometry. Equine vet. J. Suppl. 23, 45-49

Barrey, E., F. Desliens, D. Poirel, S. Biau, S. de Beauregard and B. Langlois (2000): Mesures du modèle et des allures chez les jeunes chevaux destinés au dressage: comparaison des races françaises, allemandes et espagnoles. 26ème Journée de la recherche équine, 1 er Mars 2000, 89-97

Barroil E. (1887): L'art equestre. Ed. Rothshild, Paris

Burn, J. F., A. Wilson and G. P. Nason (1997): Impact during equine locomotion: techniques for measurement and analysis. Equine vet. J. Suppl. 23, 9-12

Farley, C. T. and C. R. Taylor (1991): A mechanical trigger for the trotgallop transition in horses. Sci. 253, 306-308

Marey, J. (1873): La machine animale. Réimpression par les Editions Revue EPS (Paris) ${ }^{\circ}$

Tamura, T., M. Sekine, M. Ogawa, T. Togawa and Y. Fukui (1997): Classification of acceleration waveforms during walking by wavelet transform. Methods Inf. Med. Dec. 36, 356-9

Dr. Sophie Biau

Ecole Nationale d'Equitation Terrefort

BP 207

F-49400 Saumur

Recherche-eme@cadrenoir.tm.fr 